\title{
Majority-minority relations in a changing context
}

\author{
SHINOBU KITAYAMA \\ Kyoto University
}

\begin{abstract}
In the present article it is proposed that a person's readiness to acknowledge other views varies as an inverse function of his expectancy concerning the extent to which he can maintain favorable self-evaluation by continuously standing for his own view. Based on this idea, influence processes between a majority and a minority in a group discussion are explored. A summary of experimental data is presented, showing that: 1) A majority member, but not a minority member, is more likely to insist on his own view when he previously failed in an important, but irrelevant task than when he succeeded in it. 2) A minority member becomes influential when majority members try to differentiate their group from another group. Some problems posed by the present rescarch are discussed.
\end{abstract}

Key words: majority-minority, social influence, attitudes, intergroup relations, group decision making.

While Moscovici and his coworkers (e.g. Moscovici, 1976; Moscovici \& Faucheux, 1972; Nemeth, 1979) have proposed that a consistent behavioral style is necessary for a minority to influence a majority, Schachter (1951) demonstrated that in a group discussion a consistent deviate (i.e. minority) is likely to be rejected as a group member by other members (i.e. majority). In order to reconcile these apparently contradictory suggestions, it should be necessary to take into account psychological states of the person upon whom influence is being attempted. Specifically, the amount of influence that a minority exerts on a majority may vary depending on the majority's readiness for acknowledgment of other views, and vice versa.

Assume that a man has a motivation to evaluate himself favorably. It is then hypothesized that a man is ready to acknowledge other views when he expects that he will not satisfy his motivation for favorable self-evaluation, at some future

1 The author is now at The University of Michigan. Requests for reprints should be addressed to: Shinobu Kitayama, Research Center for Group Dynamics, Institute for Social Research, The University of Michigan, Ann Arbor, Michigan 48106 USA. time, if he continues to stand for his own view. On the other hand, he is reluctant to acknowledge other views when he expects he will satisfy this motivation if he continues to stand for his own view.

There are, of course, many factors which determine this expectation of members in a group discussion. The author has proposed two possible determinants of it; a) social support for a member's own view, and b) the presence of an outgroup. Each of them is examined in the following sections.

\section{Social Support}

In a group discussion, if other things being equal, a member whose opinion had large amount of social support (i.e. majority) could be convinced of the validity of that opinion. Furthermore, his self-evaluation would be more or less affected by the validity of his opinion. ${ }^{2}$

2 Of course, this assumption might not be generally justified. In the real world, a person could evaluate himself on various dimensions (e.g. his ability to do some task, to play sports, or to play some musical instrument, etc.). Thus, he might not mind even if his opinion on some topic turned out to be invalid. However, in the experiments to be reported below, the validity of an 
Accordingly, he would expect that he could evaluate himself favorably by continuously standing for that valid opinion, and thus would be reluctant to acknowledge other views. On the other hand, a member whose opinion had only small amount of social support (i.e. minority) would be ready for acknowledging other views because the member would expect that he could not evaluate himself favorably by continuously standing for that invalid opinion.

Further, when a person was more motivated to evaluate himself favorably, his expectation of possible satisfaction of this motivation would be more salient for him, and hence would have more effect on his readiness for acknowledgement of other views. Therefore, when a person was more motivated to evaluate himself favorably, if his opinion had large amount of social support (i.e. if he was in a majority), his expectation of possible satisfaction of this motivation would be more salient for him, and thus he would be more reluctant to acknowledge other views. On the other hand, if his opinion had small amount of social support (i.e. if he was in a minority), his expectation of possible dissatisfaction of this motivation would be more salient for him, and thus he would be readier to acknowledge them.

When a person fails in a significant task, he may be temporarily motivated to restore favorable appraisal of himself (cf. Walster, 1965). If this is the case, a person whose opinion had large amount of social support would be more reluctant to acknowledge other views, and a person whose opinion had small amount of social support would be readier to acknowledge

opinion was the most salient cue for subjects' selfevaluation because other cues were excluded from the experimental situations. In order to fully understand dynamic relationship between selfevaluations on various dimensions, however, it would be imperative to understand structures and functions of self (cf. Markus, 1977). them, after having failed in such a task than after having succeeded in it.

In one experiment (Kitayama, In press), data which support the above proposition concerning a person who has large amount of social support for his opinion were obtained. At first, male high school students worked on a task which allegedly measured their "English ability." Following this task, the subjects discussed in a group what principle to follow in helping a juvenile delinquent. They were asked to choose either Punishment or Love principle. Subsequently, each subject was led to believe that he was in a majority (i.e. his opinion had large amount of social support) and that a minority who proposed a new principle was present. It was found only for the subjects who had chosen Punishment principle that the majority members were more likely to hold fast to their opinion when they were told that their result of the prior task had been poor than when they were told it had been good. No significant effect was found for the subjects who had chosen Love principle. This might suggest that the phenomenon is restricted only to people with certain personality characteristics.

In a subsequent experiment, ${ }^{3}$ a condition in which subjects were led to believe they were in a minority was added. Male high school students were run in a group of twelve. At first each subject worked on an "English ability test." Subsequently, the twelve subjects discussed what principle to follow in helping a juvenile delinquent. They were asked to choose either Punishment or Love principle. Half of the subjects were then led to believe that they were in a majority.

3 This experiment was conducted at the Shizuoka Prefectural Haibara High School. The author thanks the teachers and students of the high school for their help in running the experiment. He is also indebted to Mr. R. Hitokoto and Mr. Y. Rachi, who served as experimenters. 
The other half were led to believe that they were in a minority. Subjects in each of the two conditions were halved and assigned to either Success or Failure condition. Those in the Success condition were told that their result of the piror test had been good while those in the Failure condition were told it had been poor.

Each subject was then required to rate Punishment and Love principles on a scale ranging from "very much against it (1)" to "very much for it (9)." Since most of the subjects chose Punishment principle, a few subjects in each cell who chose Love principle were omitted from the analysis. A score of relative amount of approval for his opinion (Punishment principle) was obtained, for each subject, with the score for Love principle subtracted from the score for Punishment principle. Mean ratings are presented in Fig. 1. An analysis of variance showed a significant main effect for MajorityMinority, $F(1,53)=5.60, p<.05$, and a marginally significant Majority-Minority $\times$ Success-Failure interaction, $F(1,53)=$ $3.08, p<.10$, which was the result of greater relative self-approval for subjects' own opinion after the failure than after the success in the Majority condition $(p<$ $.07)$, but no significant difference in the Minority condition $(F<1)$.

The result of the Majority condition

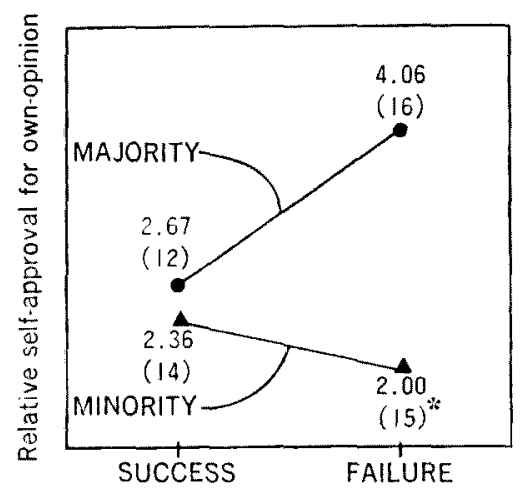

Fig. 1. Relative self-approval for own opinion.

* The number of subjects is given in parentheses. replicated the prior finding, indicating a majority member becomes more reluctant to acknowledge other views when he is motivated to evaluate himself favorably. The result in the Minority condition is not, however, conclusive. It was predicted that a minority member would be readier to acknowledge other views after the failure than after the success, but the result showed no significant difference between the Success and the Failure conditions $(F<1)$ although the difference was in the predicted direction. One possible explanation is that the subjects in the Minority condition might have thought their opinion was somewhat valid, which was indicated by the non-significant difference between Minority-Success and its Majority counterpart $(F<1)$ : If the subjects in the Minority condition had thought, as predicted, their opinion was invalid, they should have less approved their own opinion than those in the Majority condition even after the success of the prior test. It is also possible that the juvenile delinquency was such a relevant issue for the subjects (high school students) that they may have already had strong beliefs regarding it. Therefore, they might have thought their opinion was valid even when it was not supported by others.

\section{The Presence of an Outgroup}

A person's self-evaluation is determined in part by his comparison of himself with others around him, who are members of a group to which he perceives himself to belong (i.e. ingroup) (Festinger, 1954). In the preceding section, one case of this kind was examined; i.e. social support. However, the person's self-evaluation is also determined by his evaluation of the ingroup itself. Therefore, to the extent that his evaluation of the ingroup determines his self-evaluation, he will try to evaluate the ingroup favorably so as to evaluate himself favorably. 
A member of an ingroup obtains his evaluation of the ingroup by comparing the ingroup with another group whose members are excluded from the ingroup (i.e. outgroup). When an outgroup is present, therefore, the member of the ingroup may try to make the ingroup superior to the outgroup. In order to do this, the member may try to establish dissimilarity between the ingroup and the outgroup, and to attach a positive value to the dissimilarity in favor of the ingroup (Tajfel, 1978; Tajfel \& Turner, 1979). If this is the case, when an opinion that a majority of members in the ingroup had in a discussion was similar to the outgroup's view, the majority members would be inclined to feel that continuing to stand for that opinion would be detrimental to favorable evaluation of the ingroup, hence to that of themselves. Thus, the majority members would be ready to acknowledge other views.

On the other hand, when the majority's view was dissimilar to the outgroup's view, the majority members would attach a positive value to the dissimilarity in favor of themselves (cf. Ferguson \& Kelley, 1964). Accordingly, they would be inclined to feel they could evaluate the ingroup favorably, thus also themselves favorably, by continuously standing for that opinion. Hence, they would be reluctant to acknowledge other views.

To test these propositions, an experiment was conducted (Kitayama, 1981). In the laboratory, two 7-person groups were created and set apart into separate rooms. In each group male high school students discussed what principle to follow in helping a juvenile delinquent. In this discussion each subject was led to believe that he was in a majority and two minority members who proposed a new principle were present in his group. Half of the subjects were informed that the other group's conclusion was similar to the majority's opinion (Similar condition). The other half were informed that it was dis- similar (Dissimilar condition).

Subsequently, the subjects were required to select, by voting, a representative whose task was allegedly to orally set forth a conclusion of his group at the end of the discussion. A percentage of subjects who voted on one of the two minority members was, as predicted, higher in the Similar condition $(64 \%)$ than in the Dissimilar condition $(39 \%)\left(\chi^{2}(1)-8.17, p<.005\right)$, indicating that the majority members were readier to acknowledge the minority's new principle when their opinion was similar to the other group's view than when the two views were dissimilar.

\section{Concluding Remarks}

In this article, it was proposed that a person's readiness to acknowledge other views varies as an inverse function of his expectancy of possible satisfaction of his need for favorable self-evaluation. Two findings supporting this proposition were summarized. The present research, at the same time, poses some questions which are open to future research. Thus, in concluding this article, it should be justified to point out them.

In the first section, it was demonstrated that a majority becomes reluctant to acknowledge other views after having failed in a significant task than after having succeeded in it. This is because, it was so claimed, the majority expects that he can maintain favorable self-evaluation and this expectation becomes more salient to him after the failure than after the success. The result for a minority, showing that the minority's readiness to acknowledge other views is not affected by the outcome, was interpreted consistently with this reasoning. Two questions seem critical. First, in what sense do poeople expect satisfaction or dissatisfaction of their need for favorable self-evaluation when presented with such cues as being in a majority or in a minority? (This question is also relevant to the theorizing in the 
research reported in the second section, where the cue is similarity of one's own group's view to another group's view.) Do people engage in " conscious calculations" by utilizing a balance sheet? Alternatively, people may have some cognitive schema which automatically, or " mindlessly," generates such expectations and also resulting plans for future behavior in responding to those cues (Abelson, 1981; Langer, 1978. See also Nisbett \& Wilson, 1977). A second question is concerned with the effect of the outcome of the previous task. It was assumed that the failure makes more salient one's expectation as to whether he can secure favorable self-evaluation in the future. While this assumption is plausible, there should be other " side effects" of the outcome. For example, the failure may produce negative affects, and the success may produce positive ones. Although psychologists have relatively ignored effects of affective states on cognitive functions and overt behaviors, they seem to be an interesting problem especially in view of the fact that recent theories in the so-called cognitive psychology do not explicitly deal with them (See Crowder, 1976, for a review. Also see Bower, 1981; Clark \& Isen, 1982; Zajonc, 1980, for notable exceptions).

In the second section, it was shown that majority members become readier to acknowledge other views when their view is similar to another group's view than when the two views are dissimilar. It was assumed that people try to enhance their own group's evaluation, and that they do so by differentiating their group from another group on a given dimension. However, there is no saying that these assumptions always hold. Thus, it was proposed that only when one's self-evaluation is determined to a substantial degree by his own group's evaluation, he will try to enhance the latter. But this proposition remains to be experimentally tested (But see Medow \& Zander, 1965; Nagata, 1980; Zander, Stotland, \& Wolfe,
1960; Zander \& Forward, 1968, for relevant data). Furthermore, it is also an empirical problem whether people always try to differentiate their group from another group when they try to enhance their own group's evaluation. That is, under certain conditions, members of a group may be willing to accept a position advocated by another group so as to enhance their own group's evaluation.

\section{References}

Abelson, R. 1981 Psychological status of the script concept. Anterican Psychologist, 36, 715729.

Bower, G. H. 1981 Mood and memory. American Psychologist, 36, 129-148.

Clark, M.S., \& Isen, A. M. 1982 Toward understanding the relationship between feeling states and social behavior. In A. M. Isen \& A. H. Hastorf (Eds.), Cognitive social psychology. New York: Elsevier/North-Holland. Pp. 73104.

Growder, R. G. 1976 Principles of learning and memory. Hillsdale, N.J.: Lawrence Erlbaum Associates.

Ferguson, C, K., \& Kelley, H. H. 1964 Significant factors in overevaluation of own group's product. Journal of Abnormal and Social Psychology, 69, 223-228.

Festinger, L. 1954 A theory of social comparison processes. Human Relations, 7, 114-140.

Kitayama, S. 1981 Effects of intergroup relations upon status of a minority in a group. Japanese Journal of Experimental Social Psychology, 21, 429-448. (In Japanese with English summary)

Kitayama, S. In press The influence of a minority within a group. Japanese Journal of Experimenlal Social Psychology, 23.

Langer, E.J. 1978 Rethinking the role of thought in social interaction. In J. H. Harvey, W. J. Ickes, \& R. F. Kidd (Eds.), New directions in attribution research. Vol. 2. Hillsdale, N. J.: Lawrence Erlbaum Associates. Pp. 35-58.

Markus, H. 1977 Self-schemata and processing of information about self. Journal of Personality and Social Psychology, 35, 63-78.

Medow, H., \& Zander, A. 1965 Aspirations for the group chosen by central and peripheral members. Journal of Personality and Social Psychology, 
1, $22+228$.

Moscovici, S. 1976 Social influence and social change. New lork: Academic Press.

Moscovici, S., \& Faucleux, C. 1972 Social influence, conformity bias and the study of active minorities. In L. Berkowita, (Ed.), Adrances in experimental social psychology. Vol. 7. New York: Academic Press. Pp. 149-201.

Nagata, Y. 1980 Status as a determinant of conformity to and deviation from the group norm. Japancse Journal of Psychology, 51, 152-159. (In Japanese with English Summary)

Nemeth, $C .1979$ The role of an active minority in intergroup relations. In W. Austin \& S. Worchel (Eds.), The social psychology of intergroup relations. Belmont, CA: Brooks/Cole. P. $225-236$.

Nisbett, R. E., \& Wilson, T. D. 1977 Telling more than we can know: Verbal reports on mental processes. Psychological Review, 84, 231-259.

Schachter, S. 1951 Deviation, rejection, and communication. Joumal of Abnormal and Social Psycholog 1, 46, 190-208.
Tajel, H. 1978 Differentiation betweon social groups. New York: Academic Press.

Tajlel, H., \& Tumer, J. 1979 An integrated theory of intergroup contlict. In W. Austin \& S. Worchel (Eds.), The soctal phychology of intergroup retations. Belmont, CA.: Brooks/Cole. Pp. 33-48.

Walster, E. 1965 The effect of self-esteem on romantic liking. Journal of Experimental Social Pspchology, 1, 184 197.

Zajonc, R. B. 1980 Feeling and thinking: Preferences need no inferences. American Psychologist, 35, $151-175$.

Zander, A., \& Forward, J. 1968 Pasition in group, achievement motivation, and group aspiration. Journal of Personality and Social Psychology, 8, 282-288.

Zander, A., Stolland, E., \& Wolle, D. 1960 Unity of group, identification with group, and self-esteem of members. Journal of Personalily, 28, $463-478$.

(Received Oct. 25, 1982; accepted May 14, 1983) 